\title{
El activismo de los inversionistas institucionales en el gobierno de las grandes sociedades
}

Carlos Ernesto Arcudia Hernández

Universidad Autónoma de San Luis Potosí carlosarcudia@gmail.com.

\section{Resumen}

El movimiento del gobierno corporativo ha propuesto una serie de medidas que buscan resolver los problemas de separación entre el control y la gestión de las sociedades anónimas -los problemas de agencia. En este trabajo analizamos el activismo de los inversionistas institucionales como medio de control a la administración de sociedades de capital disperso. Los inversionistas institucionales en Estados Unidos han actuado por vía extraorgánica y por vía orgánica para controlar la gestión de las grandes sociedades de ese país. Si bien este activismo es una posible solución, la estructura de capital de las grandes sociedades anónimas mexicanas y los intereses de los inversores institucionales hacen un tanto difícil su actuación en nuestro país.

Palabras clave: gobierno corporativo, inversores institucionales, escuela contractualista, escuela institucionalista, activismo societario. 


\title{
The activism of institutional investors in the big companies governance
}

\begin{abstract}
The movement of Corporate Governance has proposed a series of measures which tend to solve the problems of separation between control and management of the joint-stock companies - the agency problems. The present article analyzes the activism of institutional investors as a control medium for the administration of dispersed capital companies. Institutional investors in the United States have acted through both an extra organic route and an organic one to control that country's big companies management. Although this activism is a possible solution, the capital structure of big Mexican joint-stock companies and the interests of institutional investors make their action in our country somewhat difficult.
\end{abstract}

Keywords: corporate governance, institutional investors, contractualism, institutionalism, corporate activism

\section{Introducción}

El término gobierno corporativo puede tener diferentes matices dependiendo del contexto en el cual se aplica y del investigador o entidad que lo conceptualice. Nosotros adoptaremos la definición de Larrea Martínez y Vargas García para quienes el gobierno corporativo se define como:

Los principios, normas y leyes aplicables a las corporaciones, así como a los sujetos de su ejercicio que se refieren a la propiedad o posesión corporativa, su condición o administración, la estructura y facultades de los mismos así como las medidas y prácticas tendientes a ejercer el objeto de las corporaciones y prolongar su desarrollo; entre ellas; la prevención y disminución de riesgos, la transparencia, la competitividad y, la sucesión y permanencia de los miembros (Larrea y Vargas 2009, p.22)

Ahora bien, la complejidad de la estructura de las grandes sociedades ocasiona una separación de la propiedad y del control en la empresa. Esta separación da origen a los llamados problemas de la agencia (agency problems). Dentro del gobierno corporativo se han propuesto diferentes soluciones a dichos problemas, en este trabajo analizaremos la implicación de los inversionistas institucionales en la organización y funcionamiento de las sociedades. Este activismo se analiza — como 
punto de partida - en el contexto norteamericano. Como describiremos en el apartado correspondiente, los inversionistas institucionales tienen formas de actuar de forma orgánica o extraorgánica, mediante la cual pueden controlar la gestión de la sociedad. Posteriormente trataremos la posible extrapolación de esta solución al caso mexicano.

Ahora bien, y como punto de partida de este trabajo, las preguntas con respecto al papel de los inversionistas institucionales son las siguientes:

- ¿Es posible que el activismo de los inversionistas institucionales en el gobierno corporativo sea una vía de solución a los problemas de la agencia (agency problems)?

- ¿Existen las condiciones en México para la participación de los inversionistas institucionales en el control de la gestión como en el caso de los Estados Unidos de Norteamérica?

Sostenemos como hipótesis inicial que la intervención de los inversionistas institucionales por vía orgánica o extraorgánica puede ser un medio de control de la gestión — tanto en los Estados Unidos como en México- y esto puede ser una vía de solución a los problemas de agencia.

\section{Los problemas de agencia}

La distribución del accionariado y el control de las sociedades cotizadas ocasionan los agency problems, palabra de origen anglosajón que debe ser traducida con cuidado porque la palabra agency tiene un significado más amplio en derecho mercantil. ${ }^{1}$ Así, la acepción de esta palabra proviene del campo económico en el que los problemas de agencia derivan de dos situaciones: la primera en la que un sujeto tiene la posibilidad de afectar con su comportamiento el patrimonio de otro sujeto; la segunda en la que un sujeto se beneficia de una actividad realizada mediante el esfuerzo de otra persona (Garrido, 2002, p.78).

De acuerdo con Garrido (2002, p.80), "Si el sujeto que realiza la conducta tiene intereses divergentes respecto de los del sujeto cuyo patrimonio se verá afectado

\footnotetext{
${ }^{1}$ La agencia en el derecho mercantil es un tipo de mandato representativo entre el principal y el agente; por lo tanto, solamente son problemas derivados del mandato representativo.
} 
por la actuación del primero, el Derecho debe establecer medios de control de la actuación del agent para evitar que puedan prevalecer sus intereses". Estos mecanismos pueden ser impuestos por vía legal o bien por acuerdo de las partes.

Los problemas de agencia que se pueden presentar en una sociedad de gran tamaño son básicamente tres: a) accionistas enfrentados con administradores y gestores; b) accionistas mayoritarios enfrentados a los minoritarios; y c) accionistas contra acreedores. A continuación caracterizamos estos problemas en el cuadro 1.

\section{Cuadro 1}

\section{Principales problemas de agencia}

\begin{tabular}{|c|c|c|}
\hline Accionistas vs. gestores & $\begin{array}{c}\text { Accionistas } \\
\text { mayoritarios } v s . \\
\text { accionistas minoritarios }\end{array}$ & Accionistas vs. acreedores \\
\hline $\begin{array}{l}\text { Los administradores deberán } \\
\text { conducir la sociedad } \\
\text { orientándose en el interés } \\
\text { social que coincide con } \\
\text { el de los accionistas, pero } \\
\text { esto no siempre puede } \\
\text { ser así. Estamos ante los } \\
\text { problemas generados por la } \\
\text { administración heterónoma } \\
\text { de la sociedad. }\end{array}$ & $\begin{array}{l}\text { Dado que en el seno de } \\
\text { la asamblea general de } \\
\text { accionistas donde se } \\
\text { toman las decisiones } \\
\text { importantes, una mayoría } \\
\text { de socios puede afectar los } \\
\text { derechos de la minoría. }\end{array}$ & $\begin{array}{l}\text { Una decisión adoptada por los socios } \\
\text { en beneficio propio podría acarrear } \\
\text { perjuicios a los acreedores. }\end{array}$ \\
\hline
\end{tabular}

\section{Los costos de agencia y la apatía racional}

Con el fin de limitar los conflictos de intereses y controlar la gestión de los administradores, los accionistas (principales) tendrán que adoptar una serie de medidas e incentivar a los administradores (agentes) con el fin de asegurarse que su comportamiento no les ocasione perjuicio en su patrimonio. Ahora bien, siempre existirá un cierto margen de diferencia entre los intereses de ambas partes: los costos de agencia.

Los costos de agencia se integran por la suma de "los gastos de vigilancia realizados por el principal para evitar conductas no deseadas en el agente (monitoring expenditures); los gastos de garantía (bonding costs) con los cuales el principal pretende asegurarse de que el agente no realizará determinadas acciones que irían en contra de sus intereses o de que será compensado en caso de que las realice; y, 
aquella pérdida residual (residual loss) que - a pesar de los dos gastos anteriores- sufrirá el principal por la diferencia aun pequeña que siempre habrá entre la actuación del agente y la actuación ideal que hubiese generado el máximo beneficio del principal"(Guerra Martín, 2003, p.122)

Estos costos son propios de una sociedad cotizada o abierta con independencia de la composición de su accionariado, cuando éste se encuentra disperso aumentan, ya que se presentan dos fenómenos: la apatía racional y el problema de la actuación colectiva.

La apatía racional provoca que en las sociedades abiertas los accionistas renuncien a ejercer sus facultades dominicales aun cuando tienen derecho a ello. La explicación que ha dado la doctrina económica se basa en que el accionista individual entra con mentalidad de inversionista y equipara el valor de su acción a un título de crédito y lo único que le interesa es el rendimiento de su aportación; por ende, no tiene mayor interés en intervenir en la vida social. El accionista se desentiende de la gestión y no asiste a las asambleas generales; solamente intervendrá en dos situaciones: cuando aumente su grado de participación en el accionariado o, bien, ante la falta de liquidez.

El problema de la actuación de los accionistas de manera colectiva ha sido planteado como un "dilema del prisionero" según el cual si todos los accionistas actúan estarían bien. No obstante, los inversionistas compiten entre ellos y es difícil que actúen si su actuación beneficiará a sus competidores que tengan acciones en la empresa; por lo tanto, nadie actúa y los beneficiados son los administradores.

\section{La escuela contractualista y el control del mercado}

La escuela contractualista trata de explicar los costos de agencia desde una perspectiva del análisis económico del derecho, según la cual el mercado será el encargado de llenar el vacío que deja en la sociedad la apatía de los accionistas, lo que podríamos llamar control del mercado.

El contractualismo abandona la concepción de personalidad jurídica y la teoría orgánica para explicar la sociedad anónima, explicándola como una serie de contratos entre los diversos partícipes (accionistas, administradores, acreedores, trabajadores, etc.). De acuerdo con esta teoría, los participantes basan el contrato en la eficiencia, pues pactan con la sociedad para que les permita llevar a cabo una 
actividad económica a costos menores que los del mercado (Trías Sagner, 1998, p.54 y ss). Consecuentemente, cuando el costo de actuar por vía de la sociedad es más caro que en el mercado, el partícipe saldrá de la empresa y realizará la actividad directamente en el mercado

El mecanismo de control de acuerdo con esta corriente es el propio mercado, ya sea en el de productos o en el de valores, porque si la empresa es eficiente sus productos o servicios serán preferidos por el público. Es en este último mercado donde tuvo lugar el principal mecanismo de control externo sobre las sociedades cotizadas en la década de los ochenta en EE.UU.: las tomas de control hostiles por Oferta Pública de Adquisición de Acciones (OPA). ${ }^{2}$

Sin embargo, las tomas de control por medio de las OPA decayeron en 1989 por varios factores que demostraron su ineficiencia como mecanismos de control. Entre ellos podemos citar que algunas OPA estuvieron financiadas con bonos basura que estaban garantizados con los activos de la propia sociedad objeto de la OPA, por lo cual se elevaba el nivel de apalancamiento de la sociedad en caso de ser adquirida. Otro elemento fue el atrincheramiento de los administradores quienes comenzaron a adoptar medidas defensivas como las píldoras envenenadas o los paracaídas de oro, además de que algunas legislaciones adoptaron medidas proteccionistas de las sociedades domiciliadas en su territorio. Por lo tanto, el control ejercido por el mercado decayó dando paso a la reacción por parte de la escuela institucionalista (Trías Sagner, 1998, p.68 y ss).

Ante la ineficiencia del mercado para resolver los problemas de agencia comenzaron a surgir los informes de la situación del gobierno corporativo. En Inglaterra el Reporte Cadbury puso atención especial en los órganos de gobierno de la empresa y particularmente en los directores de las empresas del Reino Unido. De los resultados obtenidos del informe se creó el código de mejores prácticas para las empresas que cotizaban en la Bolsa de Londres. El principal razonamiento del Reporte Cadbury es que a mayor independencia del consejo de administración, éste tendrá mayor vigilancia. El Reporte aporta aspectos avanzados y pone en evi-

\footnotetext{
${ }^{2}$ Según la escuela contractualista, el mecanismo de control por medio de OPA era una muestra de que el mercado ejercía un control efectivo, ya que si el valor de cotización de una empresa en el mercado estaba por debajo de su valor real se debía, sin duda alguna, a que la sociedad estaba mal gestionada; por lo tanto, habría inversionistas deseosos de adquirir tal empresa, cambiar al equipo directivo responsable de la mala gestión y con una buena gestión hacer que el valor del mercado alcanzara el valor real.
} 
dencia la relevancia de los órganos de gobierno de la empresa (Larrea Martínez et al., 2009, p.4 y ss). ${ }^{3}$

\section{La escuela institucionalista y el control regulatorio}

La escuela institucionalista que agrupa a un abanico diverso de teóricos, que aunque sustentan opiniones diversas, no comparten las tesis de la escuela contractualista, pues reaccionaron ante el fracaso como mecanismo disciplinario de la OPA proponiendo retomar el control orgánico de la sociedad; es decir, los propios accionistas deberían ser los que desde dentro de la sociedad ejercieran el control de los administradores.

Esta corriente considera que debe existir un marco regulatorio imperativo porque desde la tesis contractualista no se tiene en cuenta que varias condiciones son impuestas por los administradores a los accionistas y no por virtud de un contrato. Además, los deberes de lealtad ${ }^{4}$ y fidelidad ${ }^{5}$ de los administradores no se pueden dejar a disposición de las partes, sino que deben estar exigidos por ley (Trías Sagner, 1998, p.72 y ss). ${ }^{6}$

\section{Los problemas de agencia en México}

En Latinoamérica el principal problema de agencia surge entre los accionistas mayoritarios y los minoritarios. Como resultado los primeros se benefician a costa de los segundos a través de la expropiación, el nepotismo y la corrupción política.

\footnotetext{
${ }^{3}$ Ahora bien, una de las principales críticas de los detractores del Reporte Cadbury se centró en el carácter voluntario para sujetarse al mismo; sin embargo, su aportación abrió los ojos a los reguladores del mercado con la recomendación de que los consejos de administración contaran al menos con tres consejeros independientes y que las posiciones de presidente del Consejo y de director general fuesen ocupadas por diferentes personas (Larrea Martínez-Vargas García, 2010, p.6) ${ }^{4} \mathrm{El}$ deber de lealtad es un principio fundamental de los funcionarios de la empresa para que no utilicen su posición con el fin de obtener alguna ganancia personal de cualquier índole. Las conductas asociadas con la lealtad son la confidencialidad y los conflictos de intereses (Larrea Martínez et al., 2010, p.87) ${ }^{5}$ Eldeberdefidelidadconsisteenlaobligacióndelosadministradoresdeorientar suactuaciónalatuteladelasociedadsin tomarenconsideraciónlospropiosinteresesolos deterceros(SánchezCaleroySánchez-CaleroGuilarte, 2007,p.478). ${ }^{6}$ Entre los mecanismos de control interno que propone esta escuela se encuentran el deber de información en el seno del Consejo de Administración junto con la incorporación de consejeros independientes, cuya misión es que con la información que les proporcione la administración de la empresa puedan ejercer la función de control en el seno de los Consejos de Administración. Por último, y lo que será objeto del presente trabajo, se encuentra el activismo de los inversionistas institucionales.
} 
En efecto, la raíz de este problema surge de dos fuentes: por un lado, la estructura de gobierno corporativo de las compañías negociadas públicamente en la bolsa pública aísla a los grandes accionistas de las amenazas de tomas de control y los monitoreos; por otro, el sistema legal no protegía a los accionistas minoritarios porque las leyes son insuficientes o porque no se ejercen.

México ha modificado su legislación para tratar de defender los intereses de los accionistas minoritarios. Una de las reformas legales más importantes ha sido la adopción de un subtipo societario con un estatuto específico para las sociedades anónimas que cotizan en la Bolsa Mexicana de Valores sin ser entidades financieras: la Sociedad Anónima Bursátil (SAB). Esta nueva figura se incluye en la Ley del Mercado de Valores (LMV) de 2006. En los artículos 22 a 57 de esta ley se regula la denominación social, la administración, los deberes de diligencia y lealtad, las acciones de responsabilidad, la vigilancia, la gestión y la ejecución de negocios sociales, la asamblea de accionistas, los derechos de los socios, la emisión de acciones y las operaciones sobre los títulos acciones (Guadarrama López, 2008, pp. 9-10). ${ }^{7}$

Los accionistas mayoritarios emplean diferentes mecanismos para mantener el control, por ejemplo, empleándose en la gerencia alta, sirviendo en el Consejo de Administración, limitando el intercambio de acciones y/o formando grupos de empresarios. En el caso mexicano, de las compañías que cotizan en la Bolsa de Valores de Nueva York, el 44\% tienen un grupo de accionistas con una participación mayoritaria en la firma (Santiago Castro, Brown, Báez Díaz, 2009, p. 29).

\section{Los inversionistas institucionales}

Una característica del nuevo contexto financiero internacional es el surgimiento de un nuevo tipo de agentes financieros a escala mundial: los inversionistas institucionales. Estos inversionistas están formados fundamentalmente por tres categorías de agentes: fondos de pensiones, fondos de inversión y compañías de seguros y finanzas; éstos se caracterizan por su desigual implantación en cada uno de ellos según el país que consideremos.

\footnotetext{
${ }^{7}$ Guadarrama López (2008, p.10) señala que hasta antes de la entrada en vigor de la nueva LMV de 2006, la regulación bursátil se circunscribía a los diversos actores del mercado de valores (intermediarios, bolsa de valores, títulos), pero no a las sociedades no financieras emisoras de los títulos de acciones, a las que si bien se imponían requisitos para cotizar en la Bolsa, no se regulaba su estructura interna. El enfoque siempre fue la debida protección del mercado y del público inversionista.
} 
En sentido amplio, inversionista institucional es un concepto contrario a inversionista individual; por lo tanto, podemos considerarlo como una persona jurídica cuyo objeto es invertir en contraposición con el inversionista persona física. En México, la fracción XVII de la LMV define a los inversionistas institucionales como las personas a las cuales las leyes federales les dan ese carácter o sean entidades financieras, incluyendo cuando actúen como fiduciarias al amparo de fideicomisos que conforme a las leyes se consideren como inversionistas institucionales.

Pues bien, debemos tomar en cuenta algunos elementos que nos permitirán analizar la participación de los inversionistas institucionales: a) los inversionistas institucionales canalizan la inversión de terceros hacia una sociedad emisora, por lo que no son propiamente sus recursos los que invierten; b) el inversionistas institucional toma la decisión de la inversión de los recursos captados del público; c) el inversionista asume la gestión y control de los valores adquiridos cuando éstos son acciones de una empresa.

Estamos ante una forma de gestión colectiva de inversiones en valores en la cual pequeños inversionistas que —además de carecer de un capital suficiente como para diversificar sus inversiones, controlar el riesgo y no tener la experiencia ni el tiempo necesario para desarrollar una estrategia de inversión- "acumulan sus fondos para que sean invertidos en valores y gestionados; bien sobre la base de una estructura societaria o bien sobre una estructura fundacional o contractual"'(Tapia Hermida, 1998, p.70 y ss).

Los inversionistas institucionales son un fenómeno que proviene de los Estados Unidos, producto de varios factores, entre ellos la existencia de un mercado grande de capitales y el desarrollo de un sistema de pensiones basado en el ahorro de los trabajadores. Los cuatro principales tipos de inversionistas institucionales en Norteamérica son los fondos de pensiones, las entidades de inversión colectiva, bancos e instituciones de crédito y las compañías de seguros. 


\section{Cuadro 2}

\section{Principales categorías de inversionistas institucionales en los Estados Unidos}

\begin{tabular}{c|l}
\hline Fondos de pensiones & $\begin{array}{l}\text { Son patrimonios formados por las contribuciones de los partícipes, quienes a } \\
\text { cambio reciben el derecho, a favor del propio partícipe o de un beneficiario, } \\
\text { a percibir contraprestación en forma de renta o de capital, devengada en } \\
\text { caso de jubilación, fallecimiento o invalidez. }\end{array}$ \\
\hline \multirow{2}{*}{$\begin{array}{c}\text { Entidades de inversión } \\
\text { colectiva }\end{array}$} & $\begin{array}{l}\text { Las entidades de inversión colectiva tienen el rasgo común de recoger } \\
\text { la inversión de un grupo de personas para invertirla a su vez en valores } \\
\text { de otros inversores. }{ }^{9} \text { En México podemos ubicar un tipo especial de esas } \\
\text { sociedades de inversión: las SIEFORES. }{ }^{10}\end{array}$ \\
\hline Bancos & $\begin{array}{l}\text { En relación con los bancos e instituciones de crédito, éstos tienen limitada } \\
\text { su participación en el mercado financiero. La Glass-Steagall Act separó los } \\
\text { bancos comerciales de los de inversión; les prohibió a los primeros realizar } \\
\text { inversiones en acciones. Posteriormente, por virtud de la Bank Holding } \\
\text { Company Act, se limitó su participación a 5\% en activos de instituciones } \\
\text { no bancarias. }{ }^{11}\end{array}$ \\
\hline Compañías de seguros & $\begin{array}{l}\text { Estas empresas pueden intervenir como accionistas. También en el caso de } \\
\text { los fondos de pensiones asegurando el pago de las prestaciones o bien por } \\
\text { medio de la gestión y asesoramiento de los planes no asegurados. }\end{array}$ \\
\hline
\end{tabular}

En nuestro país merecen especial atención como inversionistas institucionales las sociedades de inversión (o fondos de inversión) que son instituciones financieras especializadas que tienen por objeto la adquisición de valores y documentos seleccionados de acuerdo con un criterio de diversificación y clasificación de riesgos

\footnotetext{
${ }^{8}$ Estos fondos pueden ser de carácter público como el California Public Employees Retirement System (CalPERS) o el Teachers Insurance and Annuity Association-College Retiement Equities Fund (TIAA-CREF) que son promovidos por los gobiernos federal, estatal o local; o bien fondos privados promovidos por las propias empresas o sindicatos y gestionados por estas mismas o por alguna otra entidad (Trías Sagner, 1999: 92).

${ }^{9}$ Según la estructura jurídica que adopten estas entidades podrán ser sociedades de inversión o fondos de inversión. En el primer caso, como su nombre lo indica, adoptan forma social; en el caso de los fondos adoptan la forma de fideicomiso (Trías Sagner, 1999: 97).

${ }^{10}$ Las Sociedades de Inversión Especializadas en Fondos de Ahorro para el Retiro (SIEFORES) tienen por objeto invertir los recursos provenientes de las cuentas individuales que reciban en los términos de la Ley del Seguro Social y de la Ley de los Sistemas de Ahorro para el Retiro. Para realizar estas inversiones, el artículo 43 de la LSAR establece determinados parámetros. Así, el régimen de inversión deberá tener como principal objetivo otorgar la mayor seguridad y rentabilidad de los recursos de los trabajadores. Como veremos posteriormente sus portafolios de inversión están normados por las circulares de la Comisión Nacional de los Sistemas de Ahorro para el Retiro (CONSAR) en cuanto a diversificación de riesgos.

${ }^{11}$ Pero a través de sus departamentos fiduciarios los bancos realizan actividades de asesoramiento y gestión de fondos de inversionistas individuales o de otros inversionistas institucionales. Esta vía de participación en las sociedades no tiene tantas restricciones y pueden actuar como simples depositarios de los títulos o bien como administradores de pleno derecho ejercitando todos los derechos de los títulos.
} 


\section{previamente establecidos. ${ }^{12}$ A continuación presentamos la clasificación de las so- ciedades de inversión.}

\section{Cuadro 3 \\ Clasificación de las sociedades de inversión en México}

\begin{tabular}{c|l}
\hline $\begin{array}{c}\text { Sociedades de renta variable } \\
\begin{array}{c}\text { Sociedades de inversión en } \\
\text { instrumentos de deuda }\end{array}\end{array}$ & $\begin{array}{l}\text { Estos fondos operan con acciones, obligaciones y demás } \\
\text { valores, títulos o documentos representativos de una deuda a } \\
\text { cargo de un tercero (De la Fuente, 2010, p.1018). }\end{array}$ \\
\hline $\begin{array}{c}\text { El portafolio de inversiones de este tipo de sociedad lo } \\
\text { conforman valores y documentos representativos de deuda. }\end{array}$ \\
$\begin{array}{c}\text { Sociedades de inversión de } \\
\text { capitales (SINCAS) } \\
\text { objeto de inversión, cuya naturaleza corresponde a acciones o } \\
\text { partes sociales, obligaciones y bonos a cargo de empresas que } \\
\text { promueven la propia sociedad de inversión y que requieren } \\
\text { recursos a mediano o largo plazo y cuyas actividades están } \\
\text { relacionadas preferentemente con los objetivos de la Planeación } \\
\text { Nacional del Desarrollo (De la Fuente, 2010 p.1024). }\end{array}$ \\
\hline $\begin{array}{c}\text { Sociedades de inversión de objeto } \\
\text { limitado }\end{array}$ & $\begin{array}{l}\text { Estas sociedades únicamente podrán invertir en los activos } \\
\text { objeto de inversión que definan sus estatutos y prospectos de } \\
\text { información dirigidos al público inversionista. }{ }^{13}\end{array}$ \\
\hline $\begin{array}{c}\text { Sociedades de inversión } \\
\text { especializadas en fondos para el } \\
\text { retiro (SIEFORES) }\end{array}$ & $\begin{array}{l}\text { Estos fondos tienen por objeto invertir los recursos provenientes } \\
\text { de las cuentas individuales que reciban en los términos de la } \\
\text { por el Retiro. }{ }^{14}\end{array}$ \\
\hline
\end{tabular}

\section{El activismo de los inversionistas institucionales}

Los inversionistas institucionales se habían abstenido de actuar en las sociedades objetivo de sus inversiones. La abstención era interpretada como un respaldo tácito a la gestión de la sociedad por parte de los administradores. En caso de no estar de

\footnotetext{
${ }^{12} \mathrm{La}$ adquisición de valores y documentos se realiza con recursos provenientes de la colocación de las acciones representativas de su capital social entre el pequeño y mediano inversionista, permitiéndole acceder al mercado de valores, contribuyendo con ello al ahorro interno, democratización del capital y al desarrollo del sistema financiero (De la Fuente Rodríguez, 2010, p.1015).

${ }^{13}$ Estos activos pueden ser valores, títulos y documentos inscritos en el Registro Nacional de Valores o listados en el Sistema Internacional de Cotizaciones; otros valores; recursos en efectivo; bienes, derechos y créditos documentados en contratos e instrumentos incluyendo operaciones financieras conocidas como derivadas (De la Fuente Rodríguez, 2010 p.1025 y ss).

${ }^{14}$ Para realizar las inversiones de los recursos de las pensiones, el artículo 43 de la LSAR establece determinados parámetros. Así, el régimen de inversión deberá tener como principal objetivo otorgar la mayor seguridad y rentabilidad de los recursos de los trabajadores. Asimismo, el régimen de inversión tenderá a incrementar el ahorro interno y el desarrollo de un mercado de instrumentos de largo plazo acorde con el sistema de pensiones.
} 
acuerdo, el inversionista institucional aplicaba la Wall Street Rule o Vote with your feet y desinvertían en la sociedad.

Este comportamiento se debe a la relación inversamente proporcional entre el grado de liquidez de la inversión en una sociedad y el grado de control; en otras palabras, mientras más control se tenga en la sociedad menor será la liquidez. El inversionista que no estaba de acuerdo con la gestión vendía sus acciones y con esto enviaba una señal de que no estaba de acuerdo con la gestión de la sociedad y la cotización descendía en detrimento de los demás accionistas, por lo que al ejercer el control los inversionistas son los que soportarían las pérdidas (De Paz Arias, 1995, p. 882 y ss).

Pero existen dos factores que alteraron esta relación: el primero es que el aumento en el volumen de los paquetes accionariales en manos de los inversionistas institucionales implica una pérdida al momento de deshacerse de dicho paquete; el segundo es que los principales partícipes del mercado son, precisamente, los inversionistas institucionales, por lo que les resulta difícil mantener una estrategia de compra y venta a corto plazo. Por lo anterior, nos encontramos ante una situación de existencia de inversionistas con grandes porcentajes de acciones y que experimentan crecientes dificultades para adoptar estrategias de inversiones a corto plazo (De Paz Arias, 1995, p. 883). ${ }^{15}$

Derivado del segundo factor surge la concentración del capital de las sociedades en manos de los inversionistas institucionales, esto puede facilitar la acción de dichos inversionistas en conjunto, pues les es más fácil ponerse de acuerdo. Por otra parte, los costos de agencia derivados de la supervisión los podrán absorber con las utilidades que obtendrán con la buena marcha de la empresa.

\footnotetext{
${ }^{15}$ En el caso mexicano, las SIEFORES tienen la obligación de diversificar sus inversiones dependiendo del tipo de SIEFORE que se trate. En efecto, las circulares de la serie 15 de la Comisión Nacional de los Sistemas de Ahorro para el Retiro (CONSAR) han establecido una clasificación de cinco tipos básicos de SIEFORES: la Siefore Básica 1 (SB1), la SB2, la SB3, la SB4 y la SB5. De esta tipología, la SB1 es la más adversa al riesgo y la SB5 es la menos adversa al riesgo. De esta manera, el régimen de inversión de las SB1 y SB2 es muy rígido; la primera tiene prohibido invertir en renta variable a través de índices accionarios y la segunda tiene una restricción del $15 \%$ de su capital. El régimen se flexibiliza medianamente para el caso de las SB3 aunque su perfil es de riesgo moderado, en particular en renta variable y bursatilizaciones se permite que la inversión sea acotada al $20 \%$ de su cartera. La SB4 y SB5 tienen mayor flexibilidad en el régimen de inversión, principalmente en renta variable al ampliarsehasta el 25 y 30\%, respectivamente (Villa, 2009, p.19 y ss).
} 
Formas de actuación de los inversionistas institucionales en los Estados Unidos de Norteamérica

Las formas de actuar de los inversionistas institucionales en EE.UU. son por vía extraorgánica o por vía orgánica. El uso de la primera vía consiste principalmente en contactos con los administradores, la adopción de un comité de defensa de los accionistas, los programas de control de la eficiencia o bien por medio de cartas recomendándoles la implementación de principios de gobierno corporativo y también la promulgación de dichos principios.

En la primera de las formas de intervención extraorgánica, los inversionistas institucionales hacen contacto informal con el Consejo de Administración para exponer sus puntos de vista y negociar soluciones a los problemas planteados en la gestión de la sociedad o su estructura interna (Guerra Martín, 2003, p. 175 y ss). En estas reuniones informales con dicho Consejo estimulan un ambiente de cooperación entre administradores e inversionistas que redunda en beneficio de todos los accionistas. Así, se convierten en un vehículo de comunicación y de mediación entre accionistas y administradores (Garrido, 2002, p. 56 y ss).

En algunas compañías americanas se ha creado el comité de defensa de los accionistas, a iniciativa de CalPERS, con el objeto de establecer un canal de comunicación formal entre accionistas y administradores (Trías Sagner, 1998, p. 219 y ss).

En cuanto a los programas de control, algunos inversionistas institucionales dan seguimiento a la evolución de las sociedades en el mercado. Como ejemplos podemos señalar que CalPERS y TIAA-CREF han creado una base de datos económicos que hacen públicos cada determinado tiempo; en dichas bases reportan el seguimiento que han hecho a más de 1000 sociedades que han sido contactadas para hacerles notar la pertinencia de adoptar principios de gobierno corporativo.

Por último, podemos citar como parte de la intervención extraorgánica la publicación de los principios de gobierno corporativo. En efecto, TIAA-CREF publicó los TIAA-CREF Policy Statement on Corporate Gobernance y CalPERS el Corporate Gobernance Market Principles.

Ahora bien, el control externo de la gestión y la adopción de principios de gobierno corporativo fueron aprobados, en los Estados Unidos, mediante la Ley Sarbanes Oxley cuyo objetivo es proteger a los inversionistas y al público en general de las operaciones económicas que realizan las empresas por medio de una mayor trans- 
parencia en la información financiera, beneficiando así, en un mayor plano, a la sociedad en general. La Ley Sarbanes Oxley obliga a las empresas que cotizan en la Bolsa de Nueva York a divulgar aspectos tales como responsabilidad corporativa, relaciones de la empresa con los auditores externo, así como un aumento de divulgaciones financieras y control interno (Blanco Dopico, Hernández Madrigal, Aibar Guzmán, 2009 pp.79 y 86).

Respecto a la actuación de los inversionistas institucionales por la vía orgánica, no es muy común que participen como miembros del Consejo de Administración. En primer lugar, su participación no alcanza el umbral necesario para nombrar a un representante por el sistema proporcional; en segundo lugar les haría mucho más difícil la salida de la sociedad en caso de querer desinvertir. Los inversionistas institucionales participan vigilando la verdadera autonomía de los consejeros independientes, así como el funcionamiento de las comisiones de auditoría, retribuciones y nombramientos sin estar presionadas por los administradores. ${ }^{16}$

Ahora bien, las dos principales estrategias utilizadas por los inversionistas institucionales en la Asamblea General de Accionistas para controlar a los administradores son las propuestas a los accionistas o shareholder's proporsals y la captación de apoderamientos o proxy fights.

Las propuestas a los accionistas son las medidas más utilizadas por los inversionistas institucionales debido a su bajo costo, puesto que si se cumplen con los requisitos de legitimación, tiempo y forma, su difusión correrá a cargo de la sociedad. ${ }^{17}$ Por último, la captación de apoderamientos consiste en reunir los votos de los demás accionistas para emitir un voto contrario a las propuestas de los administradores, incluyendo votar el reemplazo de la administración. ${ }^{18}$

\footnotetext{
${ }^{16}$ Los inversionistas institucionales vigilan la adecuada política de retribuciones de los administradores por medio de la efectiva independencia de la comisión de retribuciones. Asimismo, han propugnado por la separación del cargo de presidente del Consejo de Administración y del director general de la sociedad. Las labores de supervisión de la sociedad la realizan por medio de sistemas de evaluación de la gestión, retirando su confianza a la sociedad en caso de un mal funcionamiento o bien expresándolo a través de los medios de comunicación (Guerra Martín, 2003 p.123 y ss).

${ }^{17} \mathrm{Se}$ ha propuesto la eliminación de las barreras anti-OPA que provocan el atrincheramiento del management, la política de compensación de los directivos, el número de consejeros independientes, la previsión del sistema proporcional para el nombramiento de consejeros y adopción del sistema de voto secreto.

${ }^{18}$ Las captaciones de apoderamientos son de dos tipos: las que tienen por objeto el nombramiento de la mayoría de los miembros del consejo de administración, o bien que se adopten otro tipo de medidas. El papel de los inversionistas varía en uno u otro tipo, ya que en las primeras no han intervenido mucho, pero en las segundas sí, sobre todo en el caso de la eliminación de medidas anti-OPA.
} 


\section{El activismo de los inversionistas institucionales en México}

La posibilidad de actuación de los inversionistas institucionales en México por vía extraorgánica tiene vía libre. En efecto, el marco legal mexicano se ha adaptado a las exigencias de mayor transparencia y, por ende, se ha establecido una configuración de la administración de la $\mathrm{SAB}$ que facilita la intervención extraorgánica de los inversionistas institucionales.

El artículo 23 de la LMV establece que la administración de la SAB quedará encomendada a un Consejo de Administración y a un director general; este Consejo deberá integrarse por un máximo de veintiún consejeros, de los que una cuarta parte deberán ser independientes de acuerdo con el artículo 24 de la LMV. Además, la LMV establece la obligación de crear al interior del Consejo comisiones para vigilar las prácticas societarias y la auditoría (artículo $42 \mathrm{LMV}$ ). ${ }^{19}$

En cuanto al nombramiento de consejeros por el sistema proporcional, el artículo 16 fracción II de la LMV prevé dicho sistema para la SAB. Sin embargo, la idoneidad de este sistema es dudoso para la gran sociedad cotizada donde, ante la dispersión del accionariado, es difícil reunir la cantidad de capital necesaria para nombrar un representante ante el Consejo de Administración, aun cuando el artículo arriba citado establezca un porcentaje menor (10\% del capital social) que el establecido para la SA genérica.

Ahora bien, en cuanto a la intervención de los inversionistas institucionales en la Asamblea General, no existe la posibilidad de realizar propuestas por parte de los accionistas como en EE.UU., ya que no pueden proponer adiciones o modificaciones al orden del día. Las propuestas que pudieran realizarse tendrían que efectuarse en el marco del orden del día con el que se convoca a la Asamblea General Ordinaria de Accionistas.

Puede señalarse como vía alternativa la convocatoria a una Asamblea General Extraordinaria porque los socios — por cuya petición se convoque - tienen que

\footnotetext{
${ }^{19}$ La práctica 15 del Código de Mejores Prácticas (Consejo Coordinador Empresarial, 2010: 18) recomienda que, con el propósito de tomar decisiones más informadas, el Consejo de Administración realice las funciones de auditoría, evaluación y compensación, así como finanzas y planeación, con el apoyo de uno o varios órganos intermedios. Se sugiere que sea en forma de "comités". Esta configuración de los órganos sociales permite la vigilancia y seguimiento de su adecuado funcionamiento por parte de los inversionistas institucionales.
} 
especificar en la solicitud los asuntos que se tratarán. En ese sentido, el listón establecido por la fracción II del artículo 50 de la LMV del 10\% de los accionistas facilita más este tipo de peticiones que el $33 \%$ requerido por la LGSM.

En cuanto a la captación de apoderamientos está previsto en el artículo 192 LGSM que los accionistas podrán hacerse representar en las asambleas por mandatarios, ya sea que pertenezcan o no a la sociedad. La representación deberá conferirse en la forma que prescriban los estatutos y, a falta de estipulación, por escrito. ${ }^{20}$

\section{La renuencia de los inversionistas institucionales a intervenir en México}

Es necesario tener en cuenta que las teorías sobre la actuación de los inversionistas institucionales provienen de los Estados Unidos de Norteamérica, donde el accionariado está disperso y la actuación de los inversionistas institucionales tiende a solucionar el agency problem entre los accionistas y los administradores. Por ello, no se pueden trasladar miméticamente las medidas tomadas en EE.UU. a México.

En el caso mexicano se presenta el segundo problema de agencia; es decir, accionistas que ejercen control y accionistas minoritarios, quienes tienen intereses divergentes por los beneficios privados del control; por lo tanto, el papel del inversor institucional ante este panorama cambia. En efecto, el peso de los inversionistas institucionales es menor, ya que tendrían que enfrentarse a administradores que están respaldados por porcentajes accionariales sólidos, lo cual hace mucho más difícil su actuación.

En México, la participación de los inversionistas institucionales difícilmente alcanza una participación significativa $(5 \%)$ en las sociedades cotizadas. ${ }^{21} \mathrm{Al}$ tener umbrales de participación tan bajos, las iniciativas de activismo societario son de difícil realización, ya que difícilmente podrían recuperar el costo.

También se hace difícil la acción concertada de varios inversionistas y más si tenemos en cuenta que estamos con un accionariado concentrado. Los inversionistas

\footnotetext{
${ }^{20} \mathrm{~A}$ este respecto la práctica 3 del Código de Mejores Prácticas (Consejo Coordinador Empresarial, 2010, p. 12) sugiere que a través de un formulario que contenga en detalle la información y posibles alternativas de voto sobre los asuntos del orden del día, los accionistas puedan girar instrucciones a sus mandatarios sobre el sentido en que deberán ejercer los derechos de voto correspondientes en cada punto del orden del día de la asamblea.

${ }^{21}$ Las circulares de la serie 15 de la CONSAR limitan la inversión de las máximas al 5\% en un emisor con objeto de diversificar el riesgo de las SIEFORES.
} 
institucionales vigilan la liquidez de sus inversiones y tratan de no quedarse encerrados en un valor. Así, la participación activa disminuye el grado de liquidez de las inversiones, y en aras de mantener la liquidez los inversionistas institucionales se desentienden de la gestión social. ${ }^{22}$

\section{Valoración de la tesis del activismo de los inversionistas institucionales}

El activismo de los inversionistas institucionales como medio de control a los actos de los administradores merece una revisión crítica que se le conoce como "tesis pesimista", que sostiene que en los Estados Unidos el activismo de los inversionistas institucionales no es generalizado, sino son casos aislados donde la regla general es la pasividad. ${ }^{23}$

Según esta postura pesimista, la causa del activismo de ciertos inversores — como los fondos de pensiones norteamericanos- puede explicarse por cuestiones políticas y porque la administración pública absorbe los costos de sus decisiones erróneas. Al no estar sometidos a las presiones del mercado, a las que sí se encuentran sometidos otros inversionistas institucionales, les permite soportar los costos de su intervención.

Contra la afirmación de que al aumentar el porcentaje de participación de los inversionistas institucionales les sería más difícil la desinversión (y, por lo tanto, tendrán que intervenir en la vida social) se impone el hecho de que a los inversionistas institucionales no les interesa incorporarse a la gestión. Su incorporación a la misma les dificultaría la desinversión, pues están interesados ante todo en el rendimiento de las inversiones en el corto plazo; en cambio la adopción de estrategias activas se basa en el largo plazo. En cuanto a lo difícil de la desinversión, los inversionistas institucionales pueden realizar ventas continuas, pequeñas y constantes de forma que en un plazo de tiempo determinado realizarán la desinversión (venta por goteo). Por otra parte, la técnica de diversificar sus inversiones les per-

\footnotetext{
${ }^{22}$ Casi todas las medidas de activismo societario se traducen en una pérdida de liquidez. Si opta por el activismo, le supone un incremento de los riesgos asociados a la gestión de su cartera. Si la estrategia de gestión es desprenderse de los activos que ofrecen un mal rendimiento, el inversionista institucional sabe que el activismo societario le puede traer grandes pérdidas económicas por la combinación de un deterioro progresivo de la sociedad en que invierte y el compromiso asumido por el activismo.

${ }^{23}$ Este panorama al menos en EEUU puede deberse a que el grado de liquidez del mercado hace más fácil al inversor institucional utilizar la Wall Street Rule que intervenir en cuestiones de gobierno societario (Garrido, 2002, p.213 y ss).
} 
mite tener pequeños porcentajes de inversión en las diferentes sociedades en las que tienen participación. ${ }^{24}$

\section{Conclusiones}

De entre las soluciones que ofrece el gobierno corporativo a los problemas de agencia - ante el fracaso del control por parte del mercado — tenemos la intervención de los inversionistas institucionales en el control de la gestión de las grandes sociedades, quienes se habían abstenido de participar en la vida social y aplicaban la Wall Street Rule, pero ante el incremento de sus volúmenes de participación en la sociedad y que los principales partícipes del mercado fueran precisamente inversionistas institucionales ocasionan que salir no sea tan fácil y tengan que optar por intervenir en la vida societaria.

Las vías de acción que han escogido los inversionistas institucionales en los EE.UU. son orgánicas y extraorgánicas; de estas últimas hemos visto el contacto informal con los administradores para tratar de solucionar diferencias entre accionistas y administradores, vigilar el desempeño de los gestores y presionar para que adopten principios de gobierno corporativo.

Si bien es difícil que las vías orgánicas - a través del Consejo de Administración- hagan uso del sistema proporcional, sí vigilan la auténtica independencia de los consejeros independientes, los diferentes comités al seno del Consejo, así como una adecuada política de retribuciones de los administradores. En el seno de la Asamblea General de Accionistas actúan por dos vías: las propuestas de los accionistas y la captación de apoderamientos.

En México, la actuación de los inversionistas por vía extraorgánica es posible y ha sido facilitada en gran medida por la adopción de la SAB. La configuración del Consejo de Administración permite a los inversionistas institucionales emplear

\footnotetext{
${ }^{24}$ Además de lo anterior debemos tener en cuenta dos factores. El primero de ellos el problema de la acción colectiva, si tomamos en cuenta que en una determinada sociedad participan varios inversionistas institucionales y que normalmente compiten entre sí con base en los rendimientos de los fondos; esto pone en duda que algún inversionista quiera realizar algún esfuerzo que beneficiará de manera directa a sus competidores y que además no tendrán que aportar nada. El segundo son los costos de la intervención, si tomamos en cuenta que los inversores institucionales operan con estrictos márgenes de utilidad y que no tienen personal especializado en gobierno societario, sino más bien en análisis de inversiones; a estas entidades les resultará muy costoso entonces tomar parte en el gobierno de una empresa.
} 
las medidas extraorgánicas empleadas en los Estados Unidos de Norteamérica. La actuación por vía orgánica igualmente se ve facilitada con los nuevos umbrales de la SAB para el nombramiento de consejeros por el sistema proporcional y para la convocatoria a una Asamblea General Extraordinaria. Igualmente, el Código de Mejores Prácticas del Consejo Coordinador Empresarial facilita la captación de apoderamientos.

En cuanto a las causas concretas de por qué en México no se ha producido tampoco un activismo generalizado de los inversores institucionales está, en primer lugar, que el activismo es una solución para un problema de un sistema de control de mercado con accionariado disperso, que está concentrado en un sistema de bloques de control. Por otra parte, las reglas de diversificación de riesgos hacen que sea escaso el porcentaje accionarial de las sociedades en manos de un solo inversionista y que no supere el 5\%, que es la cifra considerada como participación importante.

El activismo de los inversionistas institucionales como medio de control a los actos de los administradores merece una revisión crítica. Y es que el activismo de los inversionistas institucionales en EE.UU. más parece una excepción y no la regla. Los inversionistas siguen aplicando la Wall Street Rule aunque son siendo renuentes a intervenir en el gobierno societario. La desinversión sigue siendo una opción utilizada, ya que si bien se ha incrementado el volumen global de ésta, la diversificación de inversiones y la venta por goteo les permiten cierta liquidez.

\section{Referencias}

Blanco Dopico, M., M. Hernández Madrigal y B. Aibar Guzmán (2009). El buen gobierno corporativo y los requerimientos informativos sobre los sistemas de control interno y riesgos: análisis de la regulación española y portuguesa en relación a otros referentes. Revista de Estudios Politécnicos VII(12): 7597.

Consejo Coordinador Empresarial (2010). Código de mejores prácticas corporativas, México

De la Fuente Rodríguez, J. (2010). Tratado de derecho bancario y bursátil, tomo II. México: Porrúa. 
De Paz Arias, J. (1995). Los inversores institucionales como medio de resolución del conflicto de intereses entre administradores y accionistas en una sociedad abierta. Revista de Derecho Bancario y Bursátil 60: 857-919.

Garrido, J. (2002). La distribución del poder en las sociedades cotizadas y los inversores institucionales. Bolonia: Real Colegio de España.

Guadarrama López, E. (2008). La Sociedad Anónima en el Derecho Mexicano, consideraciones particulares sobre la Anónima Bursátil. México: Porrúa.

Guerra Martín, G. (2003). El gobierno de las sociedades cotizadas estadounidenses, Monografía asociada a la Revista de Derecho de Sociedades 20. Madrid: Aranzadi.

Larrea Martínez, G. y S. Vargas García (2009). Apuntes de Gobierno Corporativo. México: Universidad Panamericana-Editorial Porrúa-Escuela Libre de Derecho.

Sánchez Calero, F. y J. Sánchez Calero-Guilarte (2007). Instituciones de derecho mercantil. Madrid: Thomson-Aranzadi.

Santiago Castro, M., C. Brown y A. Báez Díaz (2009). Prácticas de gobierno corporativo en América Latina. Revista Latinoamericana de Administración 43: $26-40$.

Tapia Hermida, A. (1998). Sociedades y fondos de inversión y fondos de titulización. Madrid: Dykinson.

Trías Sagnier, M. (1998). Los inversores institucionales y el gobierno de las grandes sociedades. Madrid: McGraw Hill.

Villa, J. (2009). Diagnóstico del sistema previsional privado en México. Panorama del financiamiento de infraestructura en México con capitales privados. México: Programa para el Impulso de Asociaciones Público-Privadas en Estados Mexicanos: $12-30$. ( 